\title{
Dementia and Diabetes Mellitus in Porto-Novo: Frequency and Determining Factors
}

\author{
Finangnon Armand Wanvoegbe ${ }^{1 *}$, Dieu Donne Gnonlonfoun ${ }^{2}$, Kouessi Anthelme Agbodande ${ }^{3}$, \\ Arnaulde Amoussou-Guenou Fandi ${ }^{4}$, Muriel Bernice Gnanguenon', Angèle Azon-Kouanou ${ }^{3}$, \\ Constant Adjien ${ }^{2}$, Daniel Amoussou-Guenou${ }^{1}$, Djimon Marcel Zannou ${ }^{3}$, Dismand Houinato ${ }^{2}$
}

\author{
${ }^{1}$ Internal Medicine and Endocrinology Department-Oueme-Plateau Teaching Hospital of Porto-Novo, Porto-Novo, Benin \\ ${ }^{2}$ Neurology Department-Teaching Hospital HKM of Cotonou, Cotonou, Benin \\ ${ }^{3}$ Internal Medicine Department-Teaching Hospital HKM of Cotonou, Cotonou, Benin \\ ${ }^{4}$ Saint Gérard Clinic of Porto-Novo, Porto-Novo, Benin \\ Email: *wafinarm@yahoo.fr
}

How to cite this paper: Wanvoegbe, F.A., Gnonlonfoun, D.D., Agbodande, K.A., Fandi, A.A.-G., Gnanguenon, M.B., Azon-Kouanou, A., Adjien, C., Amoussou-Guenou, D., Zannou, D.M. and Houinato, D. (2021) Dementia and Diabetes Mellitus in Porto-Novo: Frequency and Determining Factors. Open Journal of Internal Medicine, 11, 246-257. https://doi.org/10.4236/ojim.2021.114021

Received: November 19, 2021

Accepted: December 21, 2021

Published: December 24, 2021

Copyright $\odot 2021$ by author(s) and Scientific Research Publishing Inc. This work is licensed under the Creative Commons Attribution International License (CC BY 4.0).

http://creativecommons.org/licenses/by/4.0/

\begin{abstract}
Background: Chronic hyperglycemia promotes the development of degenerative diseases such as dementia. Our objective is to study dementia in diabetic patients in a hospital environment in Porto-Novo. Methods: This is a cross-sectional, prospective study with a descriptive and analytical aim that took place from May 18 to September 18, 2017, i.e. 4 months. The study population consists of all diabetic patients who consulted in the internal medicine departments of the Oueme-Plateau Teaching Hospital and at Saint Gérard clinic in Porto-Novo during the study period and who gave their enlightened consent. Results: The study included 246 patients with a mean age of $56.47 \pm$ 11.97 years. There were $172(69.9 \%)$ women, i.e. a sex ratio of 0.43 . Diabetes had been known for less than 10 years in the majority (67.9\%). Type 2 diabetics were in the majority (95.5\%). Of the 246 patients, $42(17.1 \%)$ had a Mini Mental State Examination (MMSE) less than or equal to 24. Of these 42 patients, 32 met the DSM V (Diagnostic and Statistical Manual disorders, 5th edition) criteria for dementias, i.e. a frequency of $13.0 \%$. Of the 32 demented patients, 21 (65.6\%) had vascular dementia and $34.4 \%$ had degenerative dementia. We did not note a mixed etiology. Dementia was severe in $15.6 \%$ of cases. In multivariate analysis, only age ( $\mathrm{OR}=10.09 ; 95 \%$ CI [4.19 - 24.27]; $\mathrm{p}$ $<0.001)$, arterial hypertension $(\mathrm{OR}=7.10 ; 95 \%$ CI $[1.92-26.22] ; \mathrm{p}=$ $0.003)$, and alcohol consumption $(\mathrm{OR}=3.95 ; 95 \%$ CI $[1.29-12.15] ; \mathrm{p}=$ $0.017)$ were statically associated with the onset of dementia in our diabetic patients. Conclusion: Screening for dementia should be systematic in diabetics, especially at old age.
\end{abstract}




\section{Keywords}

Dementia, Diabetes, Porto-Novo, Benin

\section{Introduction}

Human beings are confronted during their existence with much pathology which threatens their physical integrity. Among these is diabetes. In 2014, the number of people with diabetes was estimated at 422 million worldwide, compared to 108 million in 1980. Diabetes and its unmanaged or poorly managed complications have a significant impact on human life. The number of diabetes-related deaths is estimated at 5.0 million people in 2015 by the International Diabetes Federation [1]. Chronic hyperglycemia promotes the development of degenerative diseases such as dementia. It reflects a progressive degradation of cognitive functions, hampering autonomy in daily life [2]. A growing number of studies point out that adult patients with type 2 diabetes are between 1.5 and 3 times more likely to develop dementia. It appears that dementia can be a chronic complication of diabetes and should be screened for systematically [3]. All these data were obtained in developed countries and on Caucasian populations. What about sub-Saharan Africa, especially among the black population?

It is to answer this question and to allow early detection of dementia in diabetic patients that we carried out the present study, the objective of which was to study the different types of dementia in diabetic patients in a hospital environment in Porto-Novo (Benin).

\section{Methods}

This is a cross-sectional, prospective study with a descriptive and analytical aim that took place from May 18, 2017 to September 18, 2017, i.e. 4 months. The study population consists of all diabetic patients who consulted in the internal medicine services of the Oueme-Plateau Teaching Hospital and at St Gérard clinic in Porto-Novo during the study period. We performed convenience sampling by identifying all diabetic patients who consulted during the study period and gave informed consent.

Data were collected using a data sheet. It included: socio-demographic data (age, sex, ethnicity, profession, place of residence, marital status, level of education); history of high blood pressure, cerebral vascular accident (stroke), obesity, high cholesterol, alcoholism, and smoking; data on diabetes (type, age, treatment, complications of diabetes such as neuropathies, retinopathies, nephropathies, diabetic foot which have been identified on the basis of the results of the investigations contained in the medical file patient); data on dementia (frequency, cognitive impairment, severity of dementia, etiologies of dementia).

The patients were assessed for their cognitive functions through the Mini Mental State Examination (MMSE) [4] as modified and adapted to the cultural 
area of the study. Those who have had an MMSE less than or equal to 24/30 are suspected of dementia. Those with suspected dementia (MMSE $\leq 24 / 30$ ) are subject to DSM V (Diagnostic and Statistical Manual disorders, 5th edition) diagnostic criteria for the diagnosis of dementia. The severity of the dementia was assessed on the score obtained in the MMSE. In fact, a score between 20/30 included and 24/30 included in a patient meeting the DSM V criteria was considered to be "moderate dementia", while an MMSE lower than 19/30 in a patient meeting the criteria of the DSM V. DSM V was considered "severe dementia".

The HACHINSKI score was used to identify the etiologies of dementias. Indeed:

- HACHINSKI score $\geq 7$, the dementia is of vascular etiology.

- $4 \leq$ HACHINSKI score $<7$, the dementia is of mixed etiology.

- HACHINSKI score $<4$, the dementia has a degenerative etiology.

Data analysis was performed using Stata version 11 software. Tables and graphs were produced using Word and Excel 2013 software. The proportions (qualitative variables) were compared with the appropriate statistical chi-square tests. Pearson's for comparison of proportions, Student's T or Fischer's for comparison of means. A p value less than 0.05 was considered to be the threshold of significance.

\section{Results}

\subsection{Characteristics of the Study Population}

The study included 246 patients with a mean age of $56.47 \pm 11.97$ years. There were $172(69.9 \%)$ women, i.e. a sex ratio of 0.43 . Hypertensive diabetics represented $59.8 \%$ of patients and $4(1.6 \%)$ had had a stroke (Table 1$)$.

Table 1. Characteristics of the general population.

\begin{tabular}{lc}
\hline \multicolumn{1}{c}{ Variables } & Population $\mathbf{n}=\mathbf{2 4 6}$ \\
\hline Mean age (years) & $56.47 \pm 11.97$ \\
Age class (\%) & $189(76.8 \%)$ \\
$<65$ ans & $57(23.2 \%)$ \\
$\geq 65$ ans & $30.1 / 69.9$ \\
Sex (M/F) (\%) & \\
Type of diabetes (\%) & $11(4.5)$ \\
Type 1 & $235(95.5)$ \\
Type 2 & \\
Duration of diabetes (\%) & $167(67.9)$ \\
$<10$ ans & $79(32.1)$ \\
$\geq 10$ ans & $147(59.8)$ \\
Hypertension (\%) & $84(34.1)$ \\
Obesity (\%) & $23(9.3)$ \\
Alcoholism (\%) & $03(1.2)$ \\
Smoking (\%) & $04(1.6)$ \\
Vascular disease (\%) & \\
\hline
\end{tabular}




\subsection{The Results of the MMSE}

The MMSE of the patients ranged from 12 to 30 with a median of 26 . Table 2 shows the median score of the different items of the MMSE.

\subsection{Characteristics of Diabetic Patients Suffering from Dementia}

1) Frequency of dementias

Of the 246 patients, $42(17.1 \%)$ had an MMSE less than or equal to 24 .

Among these 42 patients, 32 met the DSM V criteria for dementia, i.e. a frequency of $13.0 \%$.

2) Socio-demographic characteristics of diabetic patients with dementia (DPD)

The 32 patients with dementia were between 50 and 87 years old with a mean of $69.19 \pm 8.69$ years; $22(68.7 \%)$ were female.

Table 3 shows the distribution of the socio-demographic characteristics of the DPD.

3) Clinical, therapeutic and evolutionary characteristics of diabetic patients with dementia

Table 4 shows the distribution of patients according to the clinical, therapeutic and evolutionary characteristics of DPD.

4) Characteristics of MMSE in diabetic patients with dementia

The MMSE of the patients ranged from 12 to 24 with a median of 21 . Table 5 shows the median score of the different items of the MMSE.

5) Etiologies and severity of dementias

Of the 32 diabetic patients with dementia, 21 (65.6\%) had vascular dementia and $11(34.4 \%)$ had degenerative dementia. We did not note a mixed etiology. Dementia was moderate in $84.4 \%$ (27 patients) of cases and severe in $15.6 \%$ of cases (5 patients).

\section{Research of Factors Associated with Dementia in Our Diabetic Patients}

\subsection{Univariate Analysis}

Table 6 shows the distribution of socio-demographic factors associated with

Table 2. Distribution of patients according to the MMSE characteristics.

\begin{tabular}{cc}
\hline Items & Median score [Min-Max $]$ \\
\hline Temporal orientation & $5[0-5]$ \\
Spatial orientation & $5[2-5]$ \\
Apprenticeship & $3[0-3]$ \\
Attention and calculation & $4[0-5]$ \\
Remembering & $3[0-3]$ \\
Language & $8[0-8]$ \\
Constructive praxis & $1[0-1]$
\end{tabular}


Table 3. Distribution of DPD according to socio-demographic characteristics.

\begin{tabular}{|c|c|}
\hline Characteristics & Number (\%) \\
\hline \multicolumn{2}{|l|}{ Age } \\
\hline$<65$ years & $10(31.2)$ \\
\hline$\geq 65$ years & $22(68.7)$ \\
\hline \multicolumn{2}{|l|}{ Sex } \\
\hline Male & $10(31.2)$ \\
\hline Female & $22(68.7)$ \\
\hline \multicolumn{2}{|l|}{ Matrimonial status } \\
\hline Single & $00(00.0)$ \\
\hline Married/Concubine & $20(62.5)$ \\
\hline Widower/Widow & $11(34.4)$ \\
\hline Divorcee & $01(03.1)$ \\
\hline \multicolumn{2}{|l|}{ Way of living } \\
\hline Live alone & $02(06.2)$ \\
\hline Live in family & $30(93.7)$ \\
\hline \multicolumn{2}{|l|}{ Profession } \\
\hline Pupil/Student & $00(00.0)$ \\
\hline Employee & $04(12.5)$ \\
\hline Craftsman/Worker & $02(06.2)$ \\
\hline House wife & $08(25.0)$ \\
\hline Retailer/Trader & $09(28.1)$ \\
\hline Retiree & $09(28.1)$ \\
\hline \multicolumn{2}{|l|}{ Place of residence } \\
\hline Urban & $29(90.6)$ \\
\hline Rural & $03(09.4)$ \\
\hline \multicolumn{2}{|l|}{ Level of education } \\
\hline Not educated & $13(40.6)$ \\
\hline Primary & $09(28.1)$ \\
\hline Secondary & $04(12.5)$ \\
\hline Higher & $06(18.7)$ \\
\hline
\end{tabular}

dementia.

It was found that patients who had diabetes for 60 months and over had a 3.90 times greater risk of developing dementia compared to those who had diabetes for less than 60 months. Those who had been diabetic for 95 months or more were 4.51 times more likely to develop dementia compared to those less than 95 months (Figure 1).

\subsection{Results of the Multivariate Analysis}

In multivariate analysis, only age the presence of arterial hypertension and alcohol consumption were the variables statically associated with the occurrence of dementia in our diabetic patients (Table 7). 
Table 4. Distribution of DPD according to clinical, therapeutic and evolutionary characteristics.

\begin{tabular}{lcc}
\hline & Number (n) & Percentage (\%) \\
\hline Duration of diabetes & 12 & 37.5 \\
$<10$ years & 20 & 62.2 \\
$\geq 10$ years & & \\
Type of diabetes & 00 & 0,0 \\
Type 1 & 32 & 100 \\
Type 2 & & \\
Antecedents & 29 & 90.6 \\
AHT & 04 & 12.5 \\
ACV & 17 & 53.1 \\
Obesity & 11 & 34.4 \\
Hypercholesterolemia & 08 & 25.0 \\
Alcoholism & 01 & 3.1 \\
Smoking & 01 & 3.1 \\
Diabetes complications & & 93.7 \\
Nephropathy & 06.5 \\
Retinopathy & 01 & \\
Peripheral Polyneuropathies & & \\
Diabetic foot & & \\
\hline
\end{tabular}

Table 5. Distribution of DPD according to the characteristics of the MMSE.

\begin{tabular}{lc}
\hline \multicolumn{1}{c}{ Items } & Median score [Min-Max] \\
\hline Temporal orientation & $3.5[1-5]$ \\
Spatial orientation & $4[3-5]$ \\
Apprenticeship & $3[0-3]$ \\
Attention and calculation & $1[0-4]$ \\
Recollection & $2[0-3]$ \\
Language & $7[0-8]$ \\
Constructive praxis & $1[0-1]$ \\
\hline
\end{tabular}

\section{Discussion}

In our study, the frequency of dementia was $13.0 \%$. This figure is close to $13.1 \%$ found by Feil DG et al. [5] among 65 to 74 years old in a study on the hypoglycemia and dementia risk in diabetic veterans in the United States in 2011. But the two populations are not superimposable. Abba ZI et al. [6] found a frequency 
Table 6. Distribution of patients according to factors associated with dementia.

\begin{tabular}{|c|c|c|c|c|c|}
\hline & $\begin{array}{c}\text { Dementia } \\
(\mathrm{n} \%)\end{array}$ & $\begin{array}{c}\text { No } \\
\text { dementia } \\
(\mathrm{n} \%)\end{array}$ & Total & OR $[95 \% \mathrm{CI}]$ & $\mathrm{p}$ \\
\hline \multicolumn{6}{|l|}{ Age } \\
\hline$<65$ years & $10(5.3)$ & $179(94.7)$ & 189 & 1 & - \\
\hline$\geq 65$ years & $22(38.6)$ & $35(61.4)$ & 57 & $11.25[4.58-28.16]$ & 0.001 \\
\hline \multicolumn{6}{|l|}{ Sex } \\
\hline Male & $10(13.5)$ & $64(86.5)$ & 74 & $1.06[0.47-2.38]$ & 0.88 \\
\hline Female & $22(12.8)$ & $64(86.5)$ & 172 & 1 & \\
\hline \multicolumn{6}{|l|}{ Matrimonial Status } \\
\hline Single & $0(0)$ & $8(100)$ & 8 & - & - \\
\hline Married/Concubine & $20(10.2)$ & $177(89.8)$ & 197 & 1 & - \\
\hline Widower/Widow & $11(37.9)$ & $18(62.1)$ & 29 & $5.41[2.24-13.05]$ & 0.001 \\
\hline Divorcee & $1(8.3)$ & $11(91.7)$ & 12 & $0.80[0.01-6.56]$ & 0.84 \\
\hline \multicolumn{6}{|l|}{ Way of life } \\
\hline Live alone & $2(11.1)$ & $16(88.9)$ & 18 & $0.82[0.18-3.77]$ & 0.80 \\
\hline Live in family & $30(13.2)$ & $198(86.8)$ & 228 & 1 & - \\
\hline \multicolumn{6}{|l|}{ Profession } \\
\hline Pupil/Student & $0(0)$ & $2(100)$ & 2 & - & - \\
\hline Employee & $4(10.5)$ & $34(89.5)$ & 38 & $1.38[0.40-4.74]$ & 0.617 \\
\hline Craftsman/Worker & $2(11.8)$ & $15(88.2)$ & 17 & $1.56[0.31-7.90]$ & 0.594 \\
\hline House wife & $8(30.8)$ & $18(69.2)$ & 26 & $5.18[1.77-15.20]$ & 0.003 \\
\hline Retailer/Trader & $9(7.9)$ & $105(92.1)$ & 114 & 1 & - \\
\hline Retiree & $9(18.4)$ & $40(81.6)$ & 49 & $2.62[0.97-7.09]$ & 0.057 \\
\hline \multicolumn{6}{|l|}{ Living environment } \\
\hline Urban area & $29(13.4)$ & $188(86.6)$ & 217 & $1.40[0.4-4.90]$ & 0.60 \\
\hline Rural area & $3(10.3)$ & $26(89.7)$ & 29 & 1 & - \\
\hline \multicolumn{6}{|l|}{ Obesity } \\
\hline Yes & $17(20.2)$ & $67(79.8)$ & 84 & $2.49[1.17-5.27]$ & 0.018 \\
\hline No & $15(9.3)$ & $147(90.7)$ & 162 & 1 & - \\
\hline \multicolumn{6}{|l|}{ Smoking } \\
\hline Yes & $1(33.3)$ & $2(66.7)$ & 3 & $3.41[0.30-38.83]$ & 0.32 \\
\hline No & $31(12.8)$ & $212(87.2)$ & 243 & 1 & - \\
\hline \multicolumn{6}{|l|}{ Alcoholism } \\
\hline Yes & $8(34.8)$ & $15(65.2)$ & 23 & $4.42[1.70-11.51]$ & 0.002 \\
\hline No & $24(10.8)$ & $199(89.2)$ & 223 & 1 & - \\
\hline \multicolumn{6}{|l|}{ Hypercholesterolemia } \\
\hline Yes & $11(21.2)$ & $41(78.8)$ & 52 & $2.21[0.99-4.94]$ & 0.053 \\
\hline No & $21(10.8)$ & $173(89.2)$ & 194 & 1 & - \\
\hline
\end{tabular}


Table 7. Factors associated with dementia in diabetic patients in multivariate analysis.

\begin{tabular}{lccc}
\hline & OR & $95 \%$ CI & p \\
\hline Age & & & \\
$\geq 65$ years & 10.09 & $4.19-24.27$ & $<0.001$ \\
$<65$ years & 1 & - & - \\
Hypertension & & & 0.003 \\
Yes & 7.10 & $1.92-26.22$ & - \\
No & 1 & - & \\
Alcohol & & $1.29-12.15$ & 0.017 \\
Oui & 3.95 & - & - \\
Non & 1 & & \\
\hline
\end{tabular}

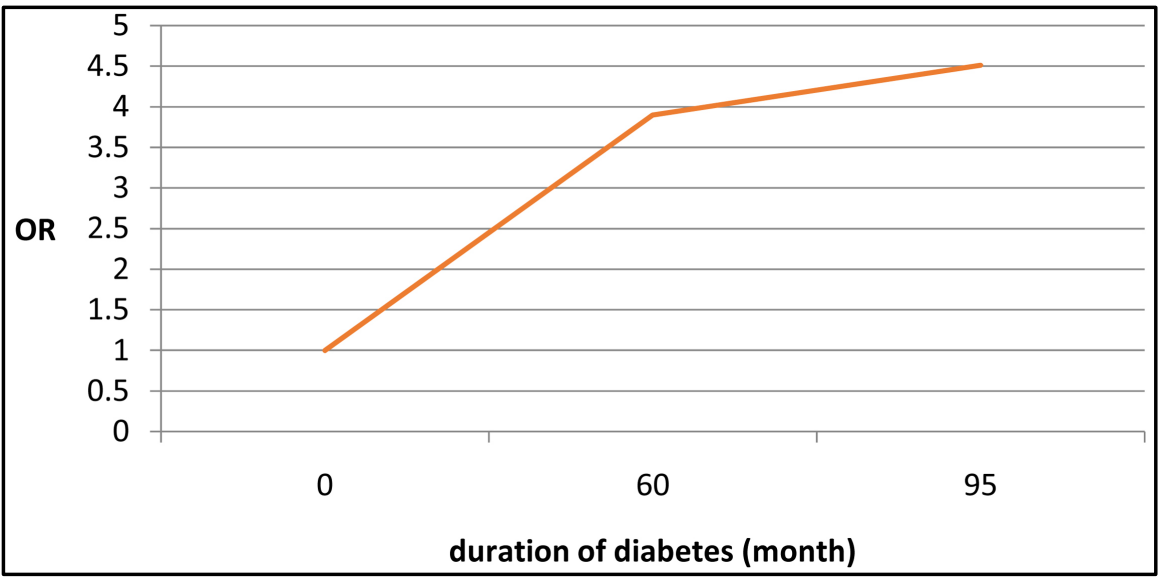

Figure 1. Risk of dementia onset depending on the duration of diabetes.

of $14.8 \%$ in a cross-sectional study on the prevalence and risk factors of cognitive dysfunction in type 2 diabetic patients in a referral hospital in Cameroon. This frequency is less than the $17.1 \%$ found by Alaama T. et al. [7] in a cross-sectional study carried out from June 09 to July 20, 2012 on the prevalence and risk factors of cognitive impairment in type 2 diabetics in Saudi Arabia. This difference could be explained by the fact that in this study, only the "Montreal Cognitive Assessment test (MoCA), the Rowland Universal Dementia Assessment Scale (RUDAS) and the MMSE were used. DSM V was not used to refine the results. Exalto L.G. et al. [8] observed a frequency of $17.3 \%$ in a study of severe diabetic retinopathy and the risk of dementia in 29,961 type 2 diabetic patients in the United States from 1998 to 2008. Likewise a study by Sinclair AJ et al. [9] in 2000 in the United States on cognitive dysfunction in a group of type 2 diabetics and a group of non-diabetics found a frequency of $29 \%$ in the group of diabetics. This last study concerned diabetics aged 65 and over and only MMSE was used unlike ours where MMSE and DSM V were used for the diagnosis of dementias. A study by Khullar S et al. [10] on the prevalence and indicators of 
cognitive impairment in type 2 diabetes found a frequency of $33.7 \%$. This high frequency can be explained by the fact that the number of subjects was higher than that of our study: 516. During this study, in addition to the MMSE, the "Trial making tests-A and B" (TMT-A and TMT-B) which are less sensitive than DSM V for the diagnosis of dementias. Our frequency of $13.0 \%$ is higher than the $11 \%$ of Whitmer R.A. et al. [11] in a study of hypoglycemic episodes and the risk of dementia in elderly patients with type 2 diabetes. This study was conducted from 1980 to 2007 in the United States. Bruce D.G. et al. [12] observed in their study of cognitive impairment, physical disability and depression in elderly diabetic patients, a frequency of $10.8 \%$ in 2003 . Another study by Lin C.H. et al. [13] on hypoglycemic episodes and the risk of dementia in diabetes mellitus found a frequency of $7.2 \%$ in Taiwan. All of these lower frequencies could be explained by the fact that these studies had much larger sizes than ours. For most of them, the diagnostic tools were not as sensitive as those used in our study. In our study, the mean age of diabetic patients with dementia was 69.19 years \pm 8.69. This result is close to the $70.6 \pm 8.6$ years observed by Exalto L.G. et al. [8]. It is greater than the $60.4 \pm 8.76$ years found by Alaama T. [7]. This difference can be explained by the fact that in this last study, the number of diabetic patients (171) was lower in ours. All studies have shown old age as a risk factor. In our study, $68.7 \%$ of patients with dementia were over 65 years of age. Also the prevalence of dementia increased with age. From 5.3\% before 65, it was $38.6 \%$ after 65 . The study by Feil D.G. et al. [5] shows that dementia in diabetic patients is closely related to age. In fact, the prevalence, which was $13.1 \%$ in patients aged 65 to 74 , increased to $24.2 \%$ in those aged 75 and over. With age, the brain atrophies. Since neurons do not renew themselves, apoptosis or programmed cell death inevitably occurs.

It is found preferentially in the frontal cortex, the temporal cortex, the amygdala ... The hippocampus is part of the limbic system just like the amygdala and plays a central role in memory. A study was carried out in Japan by Hayashi $\mathrm{K}$. et al. [14] on the association between cognitive dysfunction and hippocampal atrophy in older people with type 2 diabetes. It considered 61 diabetic patients and 53 non-diabetic controls. Hippocampal atrophy was assessed using MRI data from each patient. At the end of the study, it was observed that this impairment was higher in diabetics than in controls. These two parameters: old age and diabetes combined, therefore increase the risk of these brain lesions and consequently that of dementia. Twenty-nine (90.6\%) of our diabetic patients with dementia were hypertensive. Hypertension increased the risk of dementia 7.1 times. Khullar S. et al. [10] found that hypertensive diabetics were 3.7 times more likely to suffer from cognitive impairment compared to those without hypertension. Johnson M.L. et al. [15] in a study examining the use of antihypertensive drugs and the risk of dementia in diabetic patients noted that the existence of hypertension increased the risk of dementia. Xu W.G. et al. [16] states, following a study on the risk of dementia in diabetes mellitus, strong interactions between dementia and severe hypertension. Abnormally high blood pres- 
sure is a risk of developing vascular dementia with age. This is through several factors. We have the functional factors: increased oxidative stress, endothelial dysfunction, inflammatory state in the vascular wall, disturbance of cerebral auto-regulation; and structural factors: white matter impairment (leucoaraiosis), cerebral atrophy resulting from silent micro-infarction, sequel of stroke. Diabetes is known to be a risk factor for stroke that promotes the development of vascular dementia. The presence of hypertension in diabetics therefore increases the risk of dementia. In our study, 8 (34.8\%) of the patients were alcoholics. Alcoholism increased the risk of developing dementia by 3.95 times. Khullar S. et al. [10] state that alcoholism is a risk factor for the onset of dementia in diabetics. Consumption of alcohol is harmful to the brain. Among the structural changes, a decrease in the size of the hippocampus has been demonstrated in people who drink excess alcohol. This leads to "alcoholic amnesia" which damages the ability to learn and remember. This condition promotes the development of cognitive impairment and dementia. The simultaneous effects of alcohol and diabetes in the patient therefore effectively lead to the onset of dementia. The predominant dementia was vascular (65.6\%). As diabetes is a known vascular risk factor, this result may be justified. Indeed, a review of literature shows that Biessels G.J. et al. [17] reported a double risk of vascular dementia for diabetics as opposed to non-diabetics in 2004. This is explained by the fact that diabetes contributes to premature aging of the arteries and accelerates the process of atherosclerosis. Atherosclerosis is the root cause of most vascular disorders. Diabetes is also most often associated with metabolic syndrome. It is also made up of several cardiovascular factors such as hypertension, obesity, lipid disorders ... But Xu W.G. et al. [16] found during their study a higher proportion of degenerative dementias $(74.3 \%)$. The presence of high blood pressure in diabetes is known to increase vascular risk and almost all (90.6\%) of our demented patients are hypertensive.

\section{Conclusion}

At the end of our study, the prevalence of dementia was significantly higher. The main determinants were old age, hypertension and alcoholism. The vascular etiology was the most important. It is therefore important that screening for dementia be systematic in diabetics, especially the elderly. Likewise, we must insist on the primary prevention of diabetes, its early detection and appropriate management.

\section{Conflicts of Interest}

No conflicts of interest regarding the publication of this paper.

\section{References}

[1] International Diabetes Federation (2015) Diabetes Atlas of the International Diabetes Federation (IDF). 7th Edition, International Diabetes Federation, Brussels.

[2] Baberger, G. (2004) The Contribution of Dementia in the Disablement Process and 
Modifying Factors. Dementia and Geriatric Cognitive Disorders, 18, 330-337. https://doi.org/10.1159/000080127

[3] Nguyen, S., Major, K., Demonet, J.-F., Egli, M., Smith, C., Rubli, E., et al. (2014) Diabetes and Dementia: Dangerous Links? Revue Médicale Suisse, 10, 2090-2096.

[4] Derouesne, C., Poitreneau, J., Hugonot, L., Kalafat, M., Dubois, B. and Laurent, B., On Behalf of the Cognitive AssessmentResearch Group (GRECO) (1999) The Mental-State Examination (MMSE): Apracticaltool for the Assessment of the Cognitive State of Patients by the Clinician. Consensual French Version. La Presse Médicale, 28, 1141-1148.

[5] Feil, D.G., Rajan, M., Soroka, O., Tseng, C.L., Miller, D.R. and Pogach, L.M. (2011) Risk of Hypoglycemia in Older Veterans with Dementia and Cognitive Impairment: Implications for Practice and Policy. Journal of the American Geriatrics Society, 59, 2263-2272. https://doi.org/10.1111/j.1532-5415.2011.03726.x

[6] Abba, Z.I., Mboue-Djieka, Y., Mapoure, Y.N., Nkouonlack, C., Luma, H.N. and Choukem, S.P. (2017) Prevalence and Risk Factors of Cognitive Dysfunction in Patients with Type 2 Diabetes Mellitus Receiving Care in a Reference Hospital in Cameroon: A Cross-Sectional Study. Pan African Medical Journal-Conference Proceedings, 2, 1-7. https://doi.org/10.11604/pamj.cp.2017.2.28.62

[7] Alaama, T., Basheikh, M., Mitwalli, M. and Khiyami, A. (2014) Prevalence and Risk Factors of Cognitive Impairment in Patients with Diabetes. Alzheimer's \& Dementia, 10, 368-369. https://doi.org/10.1016/j.jalz.2014.05.426

[8] Exalto, L.G., Biessels, G.J., Karter, A.J., Huang, E.S., Quesenberry, C.P. and Whitmer, R.A. (2014) Severe Diabetic Retinal Disease and Dementia Risk in Type 2 Diabetes. Journal of Alzheimer's Disease, 42, 109-117. https://doi.org/10.3233/JAD-132570

[9] Sinclair, A.J., Girling, A.J. and Bayer, A.J. (2000) Cognitive Dysfunction in Older Subjects with Diabetes Mellitus: Impact on Diabetes Self-Management and Use of Care Services. All Wales Research into Elderly (AWARE) Study. Diabetes Research and Clinical Practice, 50, 203-212. https://doi.org/10.1016/S0168-8227(00)00195-9

[10] Khullar, S., Kaur, G., Dhillon, H., Sharma, R., Mehta, K., Singh, M., et al. (2017) The Prevalence and Predictors of Cognitive Impairment in Type 2 Diabetic Population of Punjab, India. Journal of Social Health and Diabetes, 5, 47-53. https://doi.org/10.4103/2321-0656.193996

[11] Whitmer, R.A., Karter, A.J., Yaffe, K., Quesenberry, C.P. and Selby, J.V. (2009) Hypoglycemic Episodes and Risk of Dementia in Older Patients with Type Diabetes Mellitus. JAMA, 305, 1565-1572. https://doi.org/10.1001/jama.2009.460

[12] Bruce, D.G., Casey, G.P., Grange, V., Clarnette, R.C., Almeida, O.P., Foster, J.K., et al. (2003) Cognitive Impairment, Physical Disabilities and Depressive Symptoms in Older Diabetic Patients: The Fremantle Cognition in Diabetes Study. Diabetes Research and Clinical Practice, 61, 59-67. https://doi.org/10.1016/S0168-8227(03)00084-6

[13] Lin, C.H. and Sheu, W.H. (2013) Hypoglycaemic Episodes and Risk of Dementia in Diabetes Mellitus: 7-Year Follow-Up Study. Journal of Internal Medicine, 273, 102-110. https://doi.org/10.1111/joim.12000

[14] Hayashi, K., Kurioka, S., Yamaguchi, T., Morita, M., Kanazawa, I., Takase, H., et al. (2011) Association of Cognitive Dysfunction with Hippocampal Atrophy in Elderly Japanese People with Type 2 Diabetes. Diabetes Research and Clinical Practice, 94, 180-185. https://doi.org/10.1016/j.diabres.2011.07.002

[15] Johnson, M.L., Parikh, N.M., Kunik, R.E., Schulz, P.E., Patel, J.V., Chen, H., et al. 
(2012) Antihypertensive Drug Use and the Risk of Dementia in Patients with Diabetes Mellitus. Alzheimer's \& Dementia, 8, 437-444.

https://doi.org/10.1016/j.jalz.2011.05.2414

[16] Xu, W.G., Qiu, C.X., Wahlin, A., Winblad, B. and Fratiglioni, L. (2004) Diabetes Mellitus and Risk of Dementia in the Kungsholmen Project: A 6-Year Follow-Up study. Neurology, 63, 1181-1186.

https://doi.org/10.1212/01.WNL.0000140291.86406.D1

[17] Biessels, G.J., Staekenborg, S., Brunner, E., Brayne, C. and Scheltens, P. (2006) Risk of Dementia in Diabetes Mellitus: A Systemativ Review. The Lancet Neurology, 5, 64-74. https://doi.org/10.1016/S1474-4422(05)70284-2 